\title{
Effect Modification by Acculturation and Education of the Association of Religion and Smoking in Immigrants
}

\author{
R. F. Gillum
}

Published online: 2 October 2010

(C) Springer Science+Business Media, LLC 2010

To the Editor:

Despite the growing secularization of American society, religious participation has repeatedly been shown to have a surprisingly strong inverse association with cigarette smoking [1]. The report of Hofstetter et al. in this journal confirms this association in an immigrant population [2]. We hypothesized further that this association might become weaker with greater acculturation and education in an immigrant population.

In a national health survey [1], 5,088 Mexican Americans aged 17 years and over had data on frequency of attendance at religious services (FARS), smoking, education, place of birth, language spoken at home, indicators of acculturation. In men and women combined, among the 1750 speaking English at home, the prevalence of smoking was strongly related to FARS (never $31.5 \%$, >weekly $6.7 \%, P<0.01$ ). This was also true among the 3079 who spoke Spanish at home (never 29.4, >weekly 7.9\%, $P<0.01)$. The same was true for men and women and those aged 17-24 years. Logistic regression analysis with smoking as dependent variable confirmed the lack of interaction between FARS and language spoken at home (men $P=0.37$, women $P=0.43$, all $P=0.44$ ).

In men and women combined, among the 2218 born in Mexico, the prevalence of smoking was strongly related to FARS (never $29.0 \%$, > weekly $4.5 \%, P<0.01$ ). This was also true among the 2505 born in the US (never 31.5 , >weekly $10.0 \%, P<0.01$ ). The same was true for men and those aged 17-24 years. In women, the association between attendance and smoking was statistically

R. F. Gillum ( $\square)$

Department of Medicine, Howard University, Washington,

DC 20061, USA

e-mail: rfg2.howard.edu@gmail.com significant in US born $(P<0.01)$ but not foreign-born $(P=0.17)$. However, logistic regression analysis with smoking as dependent variable detected no significant interaction between FARS and natality in any group (men $P=0.50$, women $P=0.34$, all $P=0.40$ ).

In men and women combined, among the 1815 with 12 or more years of education, the prevalence of smoking was strongly related to FARS (never $25.3 \%$, > weekly $4.4 \%$, $P<0.01$ ). This was also true among the 3253 with fewer than 12 years of education (never 33.5 , > weekly $10.4 \%$, $P<0.01$ ). The same was true for men and women. Logistic regression analysis with smoking as dependent variable confirmed the lack of interaction between FARS and education level (men $P=0.89$, women $P=0.25$, all $P=0.70)$.

These findings suggest that the apparent protective effect of religious participation to produce tobacco avoidance does not diminish among Mexican immigrants to the US as they and their descendents become acculturated and more educated. These analyses should be replicated in other immigrant populations.

\section{References}

1. Gillum RF. Frequency of attendance at religious services and cigarette smoking in American women and men: The Third National Health and Nutrition Examination Survey. Prev Med. 2005;41:607-13.

2. Hofstetter CR, Ayers JW, Irvin VL, Kang Sim DE, Hughes SC, Reighard F, Hovell MF. Does church participation facilitate tobacco control? A report on Korean immigrants. J Immigr Minor Health. 2010;12(2):187-97. 